\title{
¿ES LA NATURALEZA HUMANA MODIFICABLE MEDIANTE LA BIOTECNOLOGÍA? \\ Transhumanismo: del perfeccionamiento ético al enhancement
}

\author{
Héctor Velázquez Fernández \\ Universidad Popular Autónoma del Estado de Puebla
}

\begin{abstract}
Resumen: El transhumanismo considera necesaria la modificación de la naturaleza humana mediante la biotecnología, mediante la eliminación de la enfermedad, el envejecimiento y otras condiciones propias de la finitud humana, a través de la mejora de las capacidades físicas y mentales. En este artículo se discuten las propuestas de super inteligencia, super bienestar y super longevidad buscadas por el transhumanismo, así como la insuficiencia de la noción de mejora física frente a la de perfeccionamiento o crecimiento humano, como punto de partida para resolver, entre otros desafíos antropológicos que plantea el transhumanismo, si es modificable la naturaleza humana mediante la biotecnología.

Palabras clave: Transhumanismo, enhancement, perfeccionamiento.
\end{abstract}

\section{Is it human nature modifiable through biotechnology?}

Transhumanism: from ethical perfecting to enhancement.

Abstract: According to transhumanism it is necessary to modify human nature through biotechnology, to eliminate disease, aging and other conditions of human finiteness, all that through the improvement of physical and mental capabilities. This article discusses the proposals of super intelligence, super welfare and super longevity proposed by transhumanism, as well as the insufficiency 
of the concept of physical enhancement versus the human perfecting, as a starting point to solve, among other anthropological challenges approach posed by transhumanism, if human nature can be modified through biotechnology.

Keywords: Transhumanism, enhancement, perfecting.

Recibido: 13/10/2017 Aprobado: 5/11/2017

\section{Introducción. Contexto de la inquietud transhumanista}

En este texto analizaré en primer lugar el contexto cultural e intelectual en el que ha tomado especial fuerza el transhumanismo en los últimos años. Posteriormente, revisaré un par de variantes que ha tomado y las principales promesas que ha realizado como movimiento cultural, científico y filosófico. Finalmente me enfocaré en la contrastación entre la noción de mejora de capacidades físicas y mentales que propone el trashumanismo (buman enhancement) respecto de la noción de perfeccionamiento o crecimiento humano, desde una óptica de antropología filosófica; con la intención de valorar hasta qué punto la condición más profundamente humana o naturaleza humana sería realmente modificable mediante la biotecnología, como apuesta el transhumanismo. Y enumeraré una serie de desafíos que a mi juicio este movimiento deja para la reflexión filosófica.

El profesor Alejandro Llano ha resumido recientemente en una fórmula de tres promesas y tres lógicas lo que pudiera llamarse, a mi juicio, el contexto cultural en el que gravita actualmente el pensamiento occidental (Llano, 2016a; 2016b). Y dentro de él, el transhumanismo. 
$\dot{¿}$ Es la naturaleza humana modificable mediante la biotecnología?

Las tres promesas incumplidas por la modernidad, según Llano, anunciaban, en primer lugar, que el ser humano avanzaría en su conocimiento en la medida que éste se fundamentara cada vez más en la certeza y la evidencia; en segundo lugar, que el ser humano avanzaría hacia una sociabilidad más pacífica y plena en la medida que instalara la democracia como criterio de convivencia; y finalmente, que la humanidad progresaría más en la medida que se instalara el desarrollo científico como guía de crecimiento cultural.

Pues bien, en su análisis Llano señala que, algunas centurias después, el resultado no parece ser lo más halagüeño: en vez de que nuestro conocimiento haya avanzado por preferir el pensamiento afianzado en la certeza y la evidencia, tal parece que en la actualidad no es sino el relativismo lo que caracteriza la racionalidad actual. Hoy se antoja muy difícil que una postura intelectual en preferencia de otra pretenda solucionar los problemas más acuciantes del intelecto humano. El relativismo y el escepticismo parecen haber ganado casi por completo el terreno del ejercicio de la racionalidad, y no se ve claro que la certeza y la evidencia sean los distintivos del pensamiento actual. Así que en ese rubro parece haber fracasado la promesa moderna.

En cuanto a que la convivencia humana se haría más pacífica y plena en nuestras sociedades en la medida que se implementara la democracia como criterio de sociabilidad, dice Llano, tal parece que tanto en los países desarrollados como en los de economía emergente, en lugar de una convivencia democrática que apueste por una equidad justa entre los ciudadanos, estamos quizá en la sociedad más desigual que ha conocido la humanidad jamás: en la que quienes más tienen son menos y más poderosos, y quienes menos poseen 
son casi completamente vulnerables; lo cual sigue comprometiendo la convivencia pacífica del polvorín social en el que vivimos. Así que tampoco esa promesa de la modernidad parece haberse cumplido.

$\mathrm{Y}$ en tercer lugar, para Llano la promesa de que a mayor ciencia más progreso, solo podría decirse cumplida en muy parco aspecto, pues quizá tampoco estuvimos más cerca de destruir el planeta varias decenas de veces mediante una conflagración nuclear (hoy menos que nunca exorcizada), y las afectaciones climáticas por la acción humana ya han merecido la aparición del concepto de Antropoceno, para explicar que sin la modificación humana de la configuración natural no se puede justificar el cambio climático. Así que no necesariamente más ciencia trajo más progreso.

A estas tres promesas incumplidas de la modernidad, señala Llano, habría que añadir tres lógicas que parecen jalonar la acción humana actual: la lógica del mercado, la del Estado y la de los mass media.

Esto es, parece que el ser humano occidental hoy está orientando sus acciones bajo el criterio de fomentar preferentemente aquellas que le dejen un provecho, una conveniencia, una ganancia. Esa es la lógica del mercado: actuar solo en la medida que dicha acción me deje un rédito capitalizable en mi beneficio.

Pero no solo el provecho personal individualista parece estar operando como criterio actual de acción, sino que también hay una tendencia a querer actuar de modo que en cada decisión el resultado nos ponga un poco más por encima de los demás; bajo nuestro poder: la lógica del Estado. 
$\dot{¿}$ Es la naturaleza humana modificable mediante la biotecnología?

Y si ello no fuera poco, las acciones humanas actuales además de buscar el provecho y la superioridad sobre los demás, tienen en la mira que cada una de ellas nos de una notoriedad muy por encima del anonimato del resto: es la lógica de los mass media.

De tal modo que notoriedad, poder y provecho individualista; junto con relativismo intelectual, desigualdades sociales extremas y un riesgo de colapso como civilización ante los desarrollos amenazantes de la ciencia, hacen un coctel nada atractivo para las generaciones que apenas se están incorporando al mundo del conocimiento y de la acción dentro de la globalización actual.

$\mathrm{Y}$ es en este contexto, en el que ha ganado cierto éxito el atractivo de la propuesta transhumanista, que apuesta por la reconfiguración radical del ser humano mediante la biotecnología, que en parte se explica por la combinación de la lógica del mercado (quedémonos con los humanos mejorados capitalizables), la lógica del Estado (quien detende los medios biotecnológicos de modificación, ejercerá el poder sobre los demás), y la de los mass media (la popularidad como precio a la primicia de la modificación biotecnológica). En un clima intelectual de esta naturaleza, la pretensión de rehacer, reinventar, la condición humana mediante la biotecnología, cuantas veces sea necesario, apenas y suena extraño.

\section{El transhumanismo: su propuesta y sus variantes}

Hace décadas la propuesta de modificar mediante la biotecnología al ser humano era patrimonio prácticamente exclusivo de la literatura y el cine de 
ciencia ficción; y se enmarcaba en la excesiva confianza cultural que el inicio del siglo XX había heredado del positivismo.

Hoy en día la situación ha cambiado radicalmente. A pesar de las ácidas críticas que recibió el pasado siglo la llamada racionalidad tecnológica, hoy el optimismo tecnocientífico ha vuelto a encumbrarse de la mano de la propuesta filosófica, científica y cultural, conocida como transhumansimo.

Apenas es necesario recordar que fue Julian Huxley a quien se debe el concepto de necesaria transición del ser humano hacia una humanidad diferente, bajo el entendido de que la especie humana contaba ya, de quererlo, con los elementos para trascenderse a sí misma; no solo de modo global, un individuo aquí de una manera y otro allá de otra, sino en su completa integridad, como humanidad. Y así, manteniéndose como humano, el hombre se trascendería a sí mismo, realizando nuevas posibilidades de y para su naturaleza, para convertirse en una nueva humanidad.

50 años después de la primera propuesta de Huxley, ésta tomó forma en diferentes iniciativas, que de algún modo confluyen en el manifiesto de la Asociación Mundial Transhumanista (2005), según el cual, el transhumanismo como un movimiento cultural, intelectual y científico, afirma el deber moral de mejorar las capacidades físicas y cognitivas de la especie humana, y aplicar al hombre las nuevas tecnologías, a fin de eliminar los aspectos no deseados y no necesarios de la condición humana: los padecimientos, la enfermedad, el envejecimiento e incluso la condición mortal.

A poco más de 10 años de esta declaración, este movimiento ha ganado un interesante lugar en la discusión interdisciplinar acerca de los límites y 


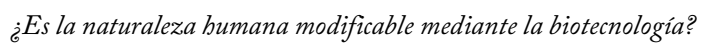

alcances, conveniencia, urgencia o viabilidad de la modificación del ser humano mediante la biotecnología, según la cual el hombre sería capaz de reinventarse y liberarse de las ataduras que la naturaleza le ha provisto en su constitución biológica y psíquica.

La reflexión sobre la modificación del hombre sobre sí mismo, no es nueva. Pero creo que en este caso en particular, dada los omnipresentes resultados de la racionalidad biotecnológica, y su combinación con las tres leyes descritas por Llano, y las promesas incumplidas de la modernidad, es importante tomar nota de los desafíos que una propuesta como la transhumanista impone a un pensamiento filosófico o cultural que pretenda mantener como eje y prioridad a la persona humana.

El tema de la mejora, de la modificación humana para llegar a niveles de mayor envergadura vital, propuesta por el transhumanismo no es tan ajeno a nosotros. Los seres humanos nos hemos ido transformando desde hace milenios en cierto producto de nuestra relación con la ciencia, con la tecnología y la cultura: el que hayamos desarrollado modelos y estructuras de educación, leyes, escritura, de organizaciones civiles, etc., así como productos de la técnica como la agricultura, la conservación y procesamiento de alimentos, etc. (Diéguez, 2016), nos ha permitido arribar a estados de actividad física y cultural inimaginables por los primeros humanos.

Sin embargo, la reflexión detonada por la mejora propuesta por el transhumanismo va algunos pasos más allá. Pues si bien es cierto que a lo largo de milenios hemos modificado nuestra convivencia y cultura, la propuesta trashumanista reclama modificaciones más ambiciosas mediante la 
biotecnología, en un sentido y alcance muy semejante al propuesto en su momento por la literatura y el cine de ciencia ficción.

Esta inquietud transhumanista no ha tomado una forma unívoca: para algunos la biotecnología nos da la oportunidad de modificar la esencia misma del ser humano; mientas que para otros, se trata simplemente de explotar las ventajas tecnológicas que nos permitan buscar mejoras a nuestras condiciones físicas y mentales.

Con un buen sentido didáctico Antonio Diéguez divide en dos los tipos principales de transhumanismo: el transhumanismo cultural y el transhumanismo tecnocientífico (Diéguez, 2017, cap. 1).

Para el transhumanismo cultural, señala Diéguez, ha llegado el momento de que el hombre supere aquellas categorías que habrían generado una visión sesgada de la realidad, y que en lugar de llevarlo a la liberación de sus atavismos culturales anquilosados, ha resultado en una división de la humanidad y de su realidad circundante, plena de segmentos culturales irreconciliables, dicotómicos, tales como las oposiciones masculino/femenino, ani$\mathrm{mal} /$ humano, viviente/máquina, natural/artificial, etc.

Según este análisis, dicotomías de esta naturaleza no hacen sino separar epistemológicamente, lo que en la realidad no es más que una continuidad: lo masculino y lo femenino serían en realidad dos caras culturales del constructo social del mismo ser humano; lo animal y humano, una diferenciación artificial que insistiría innecesariamente en fronteras para convertir al ser humano en una suerte de excepción en la Tierra y en el cosmos, que derivaría en la pretendida superioridad humana que nos ha llevado a la crisis ecológica glo- 


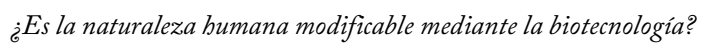

bal; mientras que la dicotomía viviente/máquina y natural/artificial separaría artificialmente realidades que ante la actual capacidad robótica de autoreplicación y la intervención transgénica en los alimentos, parecerían divisiones irrelevantes a nivel epistemológico.

El transhumanismo cultural propone la superación de estas dicotomías estériles mediante imágenes que nos lleven a pensar en un mundo sin delimitaciones. Y para ello serviría, por ejemplo, inspirarse en la figura del cyborg, que, al ser una entidad asexuada, de identidad cambiante, y ajeno a los límites entre lo vivo y lo inerte o lo natural y lo artificial acostumbraría a la mente humana a la improcedencia de las dicotomías (Diéguez, 2016).

Otro tipo de transhumanismo, al que Diéguez llama tecnocientífico, apuesta de modo directo a la urgente necesidad de aprovechar la feliz combinación de nanotecnologías, biotecnologías y tecnologías de la información, así como los desarrollos de las ciencias cognitivas y las neurociencias, para avanzar en una modificación radical de nuestra condición humana.

En este sentido la inteligencia artificial y la biotecnología juegan un papel fundamental, para permitirnos arribar a estados de mejora sustancial; una verdadera reconfiguración de la condición con la que hemos nacido, en la que se buscaría llegar incluso al alargamiento indefinido de la vida hasta no morir jamás.

Alcanzar la inmortalidad haría culturalmente irrelevante toda consideración sobre una vida ultraterrena, nos ahorraría inútiles cavilaciones sobre la responsabilidad de las acciones en esta vida y su proyección hacia la otra; o sobre la razón de la quiebra moral interna al saber qué debo hacer y en cam- 
bio realizar lo contrario de lo que debo; y lo mismo ocurriría como toda suerte de reflexiones éticas o antropológicas sobre la finitud humana.

Para ambos tipos de transhumanismo, el cultural y el tecnocientífico, la apuesta fundamental no es solo modificar el futuro humano, sino algo aún más radical: la urgencia de trastocar aquellos valores, conceptos y prácticas sociales y éticas, cuya superación nos permita tomar las riendas de nuestra propia evolución y liberarnos de la lotería genética y las limitaciones que la selección natural nos ha impuesto durante milenios; para que podamos pelear por el derecho a elegir el fenotipo que deseemos y no el que nos ha tocado en suerte (Diéguez, 2016, 49).

¿Cómo saber que se ha transitado de un estado humano a un transhumano? Para el transhumanismo ello implicaría haber alcanzado una súper inteligencia, un súper bienestar o súper felicidad, y una súper longevidad (Cortina, 2016a).

La súper inteligencia se alcanzaría mediante la fusión de la inteligencia humana y la artificial; lo que nos llevaría a una integración o verdadera ecología cognitiva: es decir, a superar la fragmentación del mundo tan propia de nuestro modo de conocer, que necesita partir del conocimiento sensible, para posteriormente clasificar, categorizar, plantear relaciones de jerarquía, etc., y así poder conocer. Según el transhumanismo, al seguir el modelo operativo de la inteligencia artificial, podríamos revertir la fragmentación del mundo como condición para nuestro conocimiento y entonces, mediante el uso, envío y aplicación de procesos informáticos ir mejorando nuestras capacidades cognoscitivas, hasta lograr que las habilidades de la inteligencia artificial 


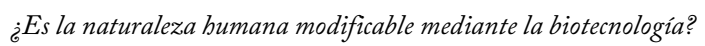

sean completamente las nuestras. Y así se habría logrado uno de los tres objetivos de la superación de la condición restrictiva humana actual: la super inteligencia.

El súper bienestar o súper felicidad radicaría en la posibilidad de decidir el humano que deseamos ser.

Y, en tercer lugar, la súper longevidad, consistiría en desarrollar todos los métodos de aplicación de nanorrobots destructores de agentes patógenos y correctores de ADN para reparar, sustituir o neutralizar estructuras dañadas, e impedir el estado de envejecimiento.

Para alcanzar estas tres conquistas de súper inteligencia, bienestar y longevidad, el transhumanismo propone dos caminos: el desarrollo de la inteligencia artificial y la implementación de la mejora de capacidades o enbancement.

La ruta de la inteligencia artificial apuesta por la creación de una mega inteligencia o mega computador en el que las inteligencias particulares sean vaciadas con la esperanza de perpetuar nuestros propios pensamientos (bajo la concepción de nuestra mente como un gran software). Una transmisión de esta naturaleza implicaría preservar nuestra personalidad en un cerebro sintético, con la finalidad de alcanzar la inmortalidad cibernética y superar la condición mortal actual ${ }^{1}$.

1 Propuesta no exenta de críticos, incluso entre los transhumanistas, pues parecer contradictorio el intentar perpetuar nuestros pensamientos individuales, cuando dicho vaciado más bien aniquilaría nuestra individualidad misma. 
La ruta de la mejora o enhancement, parte de considerar un fracaso la labor de la pretendida superación humana emprendida por la educación, la lectura humanista de los clásicos o el cultivo de las artes; que habrían generado, según el transhumanismo, una estandarizada domesticación social, más que una verdadera mejora humana. Lo que haría necesario buscar otros caminos de verdadero mejoramiento de las capacidades humanas, que nos hiciera abandonar la precariedad de las facultades en nuestra condición actual.

Para los transhumanistas, no habría de descartarse una antropotécnica que a través de la eugenesia y la manipulación genética nos dotara de seres humanos objetiva y verificablemente mejorados ${ }^{2}$.

\section{Cuatro desafios transhumanistas}

¿Qué desafíos impone la propuesta transhumanista a la reflexión filosófica y científica contemporánea? Me parece que, sin ánimo de simplificar demasiado, al menos se dan en cuatro direcciones, no del todo homogéneas en su tratamiento, pero a mi juicio igualmente importantes.

En primer lugar, respecto a la necesidad de distinguir entre las biotecnologias ocupadas en disminuir discapacidades o enfermedades, como las tecnologías terapéuticas, que pueden ser invasivas (cirugías, introducción de chips), no

2 Esperanza fincada en los avances actuales de la biología sintética, que ha logrado diseñar en laboratorio, por ejemplo, genes para fines específicos, capaces de hacer que las células adquieran funciones que no poseen en la naturaleza. 
$\dot{¿}$ Es la naturaleza humana modificable mediante la biotecnología?

invasivas (como la estimulación transcreaneal), reproductivas (como el diagnóstico preimplantatorio, o la fecundación in vitro), o de mejoramiento plástico y cosmético (como las prótesis, implantes, transplantes); y su diferencia respecto de las biotecnologías emergentes, ocupadas más bien en aumentar exponencialmente capacidades físicas o cognitivas que no son necesariamente disfuncionales. Entre estas estarían las técnicas derivadas de la ingeniería genética, la terapia génica, el doping, los implantes neuronales, la nanomedicina, los interfaces cerebro-máquina-ordenador, y otras aún en estado especulativo, como la transferencia mental a sustratos no biológicos o la nutrición artificial endógena. El desafío está en abordar cuál sería la pertinenpertinencia, jerarquía y prioridad entre estos dos grupos de biotecnologías: las dirigidas a la atención de enfermedades y las emergentes (Serra, 2016).

Un segundo desafío radicaría en definir qué debemos entender por naturaleza humana: si acaso un constitutivo irreductible, plástico y modificable mediante la intervención biotecnológica, o más bien una condición fija e intocable; o una posible opción intermedia. O bien una entidad más allá de la biología o la enumeración de los rasgos biológicos que nos distinguen.

Me parece un reto fundamental abordar las agudas críticas que hacen autores como Antonio Diéguez, quienes señalan que un cierto sector crítico del transhumanismo apela al riesgo de la intervención biotecnológica (sobre todo respecto al mejoramiento genético), argumentando una violencia del orden natural o un jugar a ser Dios, cuya queja no parecería sino una expresión vacía no objetivable; fruto de un imperialismo moral disimulado. $\mathrm{El}$ argumento desafiante transhumanista dice que no es posible apelar a una 
violación de la naturaleza humana para desestimar la intervención biotecnológica, precisamente porque es la inexistencia de una naturaleza humana estable y con carácter normativo lo que pretende negar el transhumanismo, sobre todo cara al desarrollo de la biología evolutiva actual.

Observa Diéguez la inviabilidad de apelar a la existencia biológica de la naturaleza humana, debido a la falta de consenso sobre si por especie se hace referencia a un conjunto de características morfológicas o de relaciones reproductivas o de relaciones filogenéticas o estrategias adaptativas, o a otro factor más allá de la inter fecundidad. Además del consenso biológico sobre la inexistencia de rasgos esenciales en una especie que sean inexistentes en otra, o que estén presentes en todos y cada uno de los miembros de una especie, que permitiera hablar de naturaleza (Diéguez, 2017, cap. 3) 3 .

3 Para Diéguez tampoco podría apelarse al genoma como rasgo de naturaleza humana esencial, violentada mediante la mejora genética transhumana, dado que para muchos el genoma humano no es sino un constructo idealizado elaborado a partir solo de una muestra representativa de personas. Además de que entre dos humanos, hay una diferencia de unos tres millones de pares de bases; y de que por otra parte, al compartir el 99\% de nuestros genes (o el 96\% si quitamos las secuencias repetidas) con los chimpancés, no se habla de que el chimpancé sea 99\% humano. A lo que habría de añadirse que nuestros genes han estado sometidos a cambios evolutivos que harían muy difícil hablar de una naturaleza humana esencial, dado que se tomarían en cuenta genes compartidos por todos los individuos a lo largo de la historia de nuestra especie, incluso futura; pero que por epigénesis nos haría imposible saber cuáles permanecerían en las generaciones futuras, pues por los procesos epigenéticos los genes se expresan de modo diverso en contextos diferentes. Todo ello hace inviable hablar de naturaleza humana invariable y fija. 


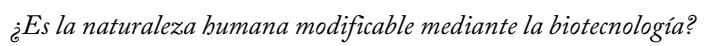

Por lo que el desafío está en la conceptualización de la naturaleza humana, de modo que nos permita justificar un valor intrínseco incondicional en el ser humano, como base para una revisión crítica del transhumanismo.

Un tercer desafío consistiría en aclarar la diferencia entre mejora o enbancement propuesta por el transhumanismo, y la noción de crecimiento o perfeccionamiento humano, que tradicionalmente se atribuye al ejercicio de los hábitos, tanto del conocimiento como de la acción, como rutas para una suerte de optimización y despliegue de nuestras facultades, que no consistiría en un mero aumento de capacidades funcionales.

$\mathrm{Y}$ un cuarto desafío, al margen de la viabilidad técnica actual de las propuestas biotecnológicas aplicables al ser humano, implicaría discutir de manera global en qué medida y con qué fundamento deberíamos o no desear una condición humana diferente a la actual: una condición en la que lo mismo estuviera ausente la enfermedad corporal o psíquica, que presente la inmortalidad completa.

De entre esos cuatro desafíos mencionados, me parece especialmente interesante el de la distinción entre mejora (enhancement) y perfeccionamiento o crecimiento humano, dado que tal diferencia está en la raíz de la aplicación esperanzada de la biotecnología sobre nuestra humanidad, para que nos permita rediseñar al ser humano que somos; y porque de ello depende la envergadura de la propuesta transhumanista de la que estemos hablando. Pues si la propuesta de intervención biotecnológica no implica modificar la naturaleza humana de manera radical sino tan solo maquillarla, disminuiría con ello la fuerza cultural de la propuesta transhumana. 


\section{Crecimientoversus mejora: los equívocos transhumanistas}

Si el ser humano se entiende como un sujeto no determinado hacia logros completos concretos, sino hacia el ejercicio de funciones que tienen resultados abiertos y combinatorias infinitas, no hay un ejercicio de libertad único hacia el cual tender. Esa es la clave del crecimiento en clave antropológica: la acción proyectada hacia el futuro no intenta completar lo inacabado (en sentido negativo) sino desplegar sin término concreto una facultad (en sentido positivo). A eso se le llama proyecto, que no es una mera compensación, como en la mejora. pues en ésta se sabe con anticipación qué capacidades debería yo tener y cómo conseguirla ejerciéndola, en función de mis circunstancias. Por ejemplo, si carezco de habilidades que no me corresponden por la edad, por mi contexto social o económico o cultural, se sabe hacia dónde he de dirigir el esfuerzo y el logro a alcanzar, que en cierto sentido es terminal.

En ese sentido la mejora es unidireccional y univoca: tiene un rango, un entorno en el cual lograrse y definirse. Aquí sí que los animales pueden servir de modelo y guía: la proporción de incremento de fuerza (las veces que una hormiga puede cargar su propio peso), el rango de visión periférica o de advertencia sensible, e incluso el ensayo y error de los logros funcionales (operativos y cognitivos) de la inteligencia artificial, que están todos ellos definidos y delimitados, son parte de un catálogo de avances, que tiene muy bien identificada el área y el alcance de la mejora, y que prácticamente puede medirse mediante un gradiente estandarizado, predeterminado y universal. 


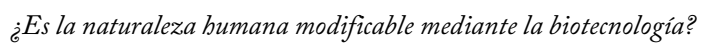

Tal y cual se hace con la edad, el rendimiento físico, e incluso el algorítmico: se conoce desde qué estado previo y hacia qué estado futuro se pretende avanzar. Por ello hablamos de mejora en la práctica de un deporte, mejora en la rapidez para leer, mejora en la habilidad para contar un chiste o preparar un platillo en su punto. Todas ellas, experiencias donde se conoce y fija un límite de referencia, y se advierte éste hasta cierto punto agotable: es altamente improbable que el humano pueda recorrer 100 metros en menos de 7 segundos, que llegue a bucear más allá de los 200 metros o memorice más de 500 números telefónicos. Toda ruta paulatina para ir llegando a esos límites, constituyen una mejora.

En esto las facultades animales sí que parecen llevarnos ventaja porque al estar finalizadas, dirigidas objetivamente para lograr el rendimiento de la sobrevivencia como tarea primordial, ponen la ruta muy clara hacia dónde iría el mejoramiento. Incluso cuando interviene el ser humano para redirigir las pulsiones naturales animales: en el amaestramiento hay un umbral restringido de logros a conseguir.

Así pues, pareciera que al identificar mejora con perfección, o mejora con crecimiento, en el caso del ser humano, en lugar de entrar en un avance, caeríamos en un retroceso. Se puede fijar el catálogo de los ámbitos de mejora y el de los umbrales de la adquisición de nuevas capacidades o competencias intelectuales, metabólicas o conductuales, y el aumento incluso en intensidad en la operación de esas dimensiones. Pero al aumentarlo con la mejora, quizá estarían dejándose de lado otros ámbitos que más que mejora, están abiertos al crecimiento. Y si eso es así, aunque la mejora sea incremento, frente al 
crecimiento es pérdida. El atleta de alto rendimiento, el plusmarquista, el fisicoculturista, el practicante de halterofilia o de natación, ha de priorizar dentro del rango de su aumento posible de capacidades, aquellas y solo aquellas que estén comprometidas con el logro que buscan alcanzar. Por ello se someten a un régimen estricto en el que sería una completa pérdida de tiempo aprender un tercer idioma, comprender las implicaciones del tercer imperativo categórico o practicar saludar como esquimal, pues el entrenamiento busca darle la habilidad para el objetivo terminal a alcanzar. La mejora solo tiene sentido en la medida que permite la exitosa consecución del objetivo. La recreación, la distracción, la práctica de actividades sin rendimiento serían en ese contexto, ociosos, evitables.

Los animales son modélicos en el aprovechamiento del tiempo: no se pueden dar el lujo de llevar a cabo actividades sin rentabilidad biológica o de carácter inútil, porque le va en ello la sobrevivencia: la propia, la del grupo o la de la especie. Incluso la recreación tiene rentabilidad biológica. Su actividad es una especie de movimiento reiterado circular, que consigue y vuelve a buscar conseguir lo conseguido, porque cada obtención tiene una caducidad y hay que reiterarla porque el alimento de hoy no es suficiente una vez que se ha deglutido y metabolizado; y una sola hembra no agota el instinto reproductivo que ha de volver a ejercerse en el nuevo periodo de celo.

En cambio, parece que la noción de crecimiento va por otra ruta que la del logro unidireccional y medible, al modo de la mejora de capacidades físicas o cognitivas. El crecimiento en cambio se parece más a un mar sin orillas: 
$\dot{¿}$ Es la naturaleza humana modificable mediante la biotecnología?

evoca algo originario, y en cierto sentido autofundante, sin más límite que el sujeto mismo.

En el crecimiento humano no parece haber un límite, un techo, como dice Leonardo Polo; lo que pondría al ser humano fuera de los límites de la temporalidad. La perfección, el futuro, la esperanza, la verdad, parece que solo tienen verdadero sentido en un umbral no topado, en el que las condiciones del aquí y el ahora no son protagonistas sino solamente contextuales, porque lo más importante en el crecimiento es el paso siguiente, no el recuento nostálgico de lo ocurrido hacia atrás, que es mera anécdota.

Si la condición humana está enraizada en el crecimiento, no se es todo el ser humano que se puede llegar a ser en ningún momento de la existencia. Dicho de otro modo: el humano puede ir a más porque nunca acaba de llegar a ser hombre, por eso "cualquier época de nuestra vida es propicia para llegar a ser más". Si el crecimiento no fuera irrestricto, la vida perdería el sentido de ser vivida. En ese sentido, el equilibrio ético es dinámico, tendencial; no estático: es un sé mejor, sé más. Es una realización en la conquista reiterada de lo humano; un ser más por dentro que se transforma al realizarse.

El hombre es un ser temporal, no temporizado; su crecimiento se logra en el tiempo, pero no tiene el tiempo como tope, por lo que crecer es la manera más perfecta de aprovechar el tiempo mismo. Todos los demás crecimientos están temporizados: por ello son mejoras, no crecimiento en sentido ético.

El tiempo humano se presenta a su vez irreversible y biográfico: la posibilidad de crecer es irrepetible. Mientras hay tiempo, puede haber crecimiento, y la única frontera es la muerte. Pero la limitación del tiempo no se presenta 
en estricto sentido como límite, sino como oportunidad. El que aún no se sea del todo lo que somos, no pretende negar la condición o naturaleza humana, sino invitar, llamar ese quién que tú eres a ser mucho más como persona: plenamente libre, sorprendentemente generoso, profundamente sabio, insospechadamente feliz (Riaza, 1996, 987).

Esta relación entre crecimiento, ética y libertad (porque para buscar ser más, hay que quererlo), es estrictamente personal e intransferible: no puedo crecer por otro, y el otro no puede perfeccionarse en mi lugar. Así que vivir en el caso humano supone crecer; que es en lo que consiste la vida lograda. Una vida dramáticamente desperdiciada lo será por haber solo acontecido, ocurrido, pasado; entretenida en la accidentalidad del solo gravitar (es el drama de los parados, o de los sin techo, o de los ninis, de los que "ahí la llevan”).

Pero la condición de vida humana es temporal en el sentido de que se vive en crecimiento irrestricto en el tiempo, pero la oportunidad está temporizada: se acaba con la muerte. Aunque se proponga la muerte como tránsito, que no es completo, pues no se suma el hombre entero a ese tránsito (Polo, 1992, 207). El advertir el límite de nuestra propia existencia, nos otorga una cierta urgencia, una cierta invitación a aprovechar el tiempo que tenemos ahora y que no vuelve, a vivir de acuerdo a lo que se es: un crecimiento como capacidad que tiene la libertad del hombre de alcanzar, a lo largo del tiempo de la vida, una perfección no limitada a priori, sino abierta.

$\mathrm{Y}$ ¿hacia dónde se dirige el crecimiento? ¿Es una tendencia ciega, que va al encuentro de la mera novedad? ¿Va descubriendo a tientas hacia dónde 
$\dot{¿}$ Es la naturaleza humana modificable mediante la biotecnología?

pudo avanzar? Preguntarse hacia dónde va el crecimiento de la persona es preguntarnos en qué cifra la búsqueda, qué desea y qué le mueve, que son las respuestas más típicamente personales, porque nos revelan una intimidad difícilmente descifrable desde fuera.

Para responderse a sí mismo la pregunta "a dónde ir con mi crecimiento", hay que advertir que sin conocimiento, el hombre no tiene adonde ir: el conocimiento mueve a la libertad y la mueve hacia algo. $\mathrm{Y}$ ¿̧hacia qué? No parece haber conocimiento sin advertencia de la realidad que me circunscribe a lo que soy. Sin esta advertencia es difícil el ejercicio de la libertad. Dicho en sentido fuerte: sin verdad no hay ejercicio de la libertad. Si no hay dirección de nuestra libertad hacia el encuentro con la verdad, no hay tarea, no hay proyecto, no hay interés, no hay explicación, no hay vida. No hay crecimiento. Y la verdad más radical que puede encontrar un nombre es su verdad personal, lo que él es: y es entonces cuando puedo crecer, porque mi libertad es poder crecer como la verdad que soy.

Sin libertad, el crecimiento es imposible; sin la posibilidad de un crecimiento siempre abierto, la libertad se queda inútil, ineficaz, absurda. Aquí entra la esperanza como parte de la libertad.

\section{La mejora versus crecimiento}

Así, en contraparte, la apuesta del enhancement parece conllevar en la propuesta de mejora un empobrecimiento del carácter humano. El no estar comprometido en particular con alguna determinación específica, el que no 
tengamos nicho ecológico propio, el que podamos realizar actividades sin rentabilidad biológica, o que para realizarlas hayamos de suspender las acciones con dicha rentabilidad (hacer acciones que no sirven para algo en especial: como el arte o el pensamiento abstracto), nos dan un margen de despliegue e irradiación de la condición humana, que hace aparecer el mejoramiento físico y mental como una especie de compulsión monocorde que clausura.

Hay nociones que pueden parecer imprecisas o usadas con ciertas licencias, pero en este caso podríamos hablar de que la mejora es plana, mientras que el crecimiento es fecundo. Esa suerte de residuo que deja por la actividad habitual, que hace al sujeto más capaz de actuar, de amar más, de admirarse más, de interesarse más, y su correlato: que hace a alguien más capaz de mentir mejor, de engañar, de salirse con la suya o de idear cómo hacer más daño, parecen no tener que ver solo con la mejora de destrezas o la pérdida de ellas, sino con algo de más empaque: el crecimiento y la clausura.

La mejora está determinada tanto en su objeto como en el modo de adquirirse y parece que el crecimiento humano es mucho más que la mejora medible en ciertos aspectos delimitados. En ello el transhumanismo pierde de vista la temporalidad y convierte la temporización en la condición humana. Sólo con una naturalización completa del hombre puede hacerse de la temporización la condición humana.

Al naturalizar completamente al ser humano, se intenta prolongar mediante la extensión de las capacidades humanas una existencia que de cualquier modo será precaria. Se trata de retrasar infinitamente el estatuto de 
$\dot{¿}$ Es la naturaleza humana modificable mediante la biotecnología?

la temporización, que siempre tiene caducidad. Por ello al final la postura no debería conformarse con una cierta mejora sino apostar a la eternidad mediante la eliminación de la muerte.

Así, desde el crecimiento ético se redimensiona la mejora de capacidades físicas, se les da un marco y un sentido y no se vuelve un fin en sí mismo; y viceversa: desde la mejora física en términos intelectuales o de rendimiento, podría abonarse en una vida más saludable, pero no necesariamente más plena o más humana, solo desde la mejora física.

No intento en estas líneas poner en entredicho la propuesta transhumanista solo por insistr en una obsesiva condición mortal humana, o porque debamos conformarnos con nuestro propio estatus precario y enfermizo, sino porque la condición humana está profundamente enraízada en el crecimiento, que no tiene tope a superar, ni record a alcanzar. Por ello, en ningún momento de su existencia, el ser humano llega a ser todo el ser humano que puede llegar a ser.

Dicho de otro modo: el hombre puede ir a más porque nunca acaba de llegar a ser hombre (Polo, 1992, 112; Torres, 2016, caps. 5 y 6); y no porque ya siéndolo, pero en sentido precario, quiera abandonar una condición ya alcanzada pero limitada, para ir tras otra más actualizada y de ahí a otra y a otra más, como quien hiciera un updating.

No parece radicar en ello nuestra condición, por la que, repito, el hombre puede ir a más porque nunca acaba de llegar a ser todo el hombre que puede ser, y por lo que cualquier época de nuestra vida es propicia para que lleguemos a ser más. 
Héctor Velázquez

\section{Epílogo: retos intelectuales del transhumanismo}

Para finalizar, los problemas a repensar a partir de los cuatro desafíos transhumanistas mencionados, nos deben llevar a replantear el papel y alcances de la biotecnología, a establecer criterios para regular la investigación científica y aclararnos cuándo debe ésta orientarse al mejoramiento humano. Nos debe animar a definir si el cuerpo humano es sólo un soma evolucionado, o también función, acción y significado. Y cuál es el papel de la historia, la socialización y la biografía en la constitución de la naturaleza humana, que le dote de un valor intrínseco incondicional, llamado dignidad.

Para responder a los desafíos transhumanistas no bastan los códigos deontológicos, sino un abordaje del fundamento normativo de la naturaleza humana, de las definiciones sobre el hombre, la ciencia y la ética.

Pero también reclama un repensamiento sobre la noción de libertad: si ésta ha de entenderse preferentemente como creatividad opuesta a necesidad natural, o si la libertad es el recurso para oponernos al carácter incompleto y disminuido de nosotros mismos, o bien si la libertad es el último rasgo de nuestra sobrevivencia y no debiéramos limitarla. En últimos términos, si la libertad es una realidad abierta al infinito de posibilidades o un engaño que nos hace soñar que mientras más se avanza en la mejora transhumana, por otro lado menos se avanza en la perfección personal humana.

Y desde luego, debe llevarnos a considerar el papel de la interdisciplinariedad, que nos lleve a repensar la biotecnología, su relación con el derecho, la dinámica de la sociedad y la economía. Y por último, nos debe animar a 
$\dot{¿}$ Es la naturaleza humana modificable mediante la biotecnología?

abordar en qué consistiría la especificidad humana, que reclama una redefinición de la biotecnología con el hombre como único fin: el hombre real, no el ideal; el hombre posible, a partir de lo que es; no solo a partir de cómo lo imaginamos. Ello nos impone el reto de plantear el sentido y alcance de la condición mortal, base de nuestra identidad finita: que nos lleve a distinguir qué tenemos de peculiar que, aunque biográfico, permanece; y qué de común, que como lo mortal es de todos, pero especial de cada uno.

Porque, desde el punto de vista del crecimiento, el hombre debe (a) llegar a ser (con sus acciones en el tiempo) (b) lo que debe ser (cumplimiento de su esencia) (c) a partir de lo que ya es (situación biográfica actual).

La mejora trashumanista difumina la fase (b): lo que el hombre debe ser; reinventa con la biotecnología la fase (c): lo que ya es, para intentar ir a parar a la posthumanización.

\section{Bibliografía empleada}

A. Aguti, Natura Umana. Un'indagine storico-concettuale, Trieste, Meudon, 2010.

D. Bermejo, "Las aventuras del paradigma antrópico: humanismo, transhumanismo, posthumanismo", en Diego Bermejo (ed.), Pensar después de Darwin. Ciencia, filosofía y teología en diálogo, Madrid, Salterrae, 2014.

A. Cortina (a), "Transhumanismo y singularidad tecnológica. Superinteligencia, superlongevidad y superbienestar”, en Albert Cortina y Miquel-Àngel Serra (cords.), Humanidad. Desafíos éticos de las tecnologías emergentes, Madrid, Ediciones Internacionales Universitarias, 2016.

A. Cortina, M.-À. Serra (eds.) (b), Singulares. Ética de las tecnologías emergentes en personas con diversidad disfuncional, Madrid, Ediciones Internacionales Universitarias, 2016. 
Héctor Velázquez

A. Diéguez, "Transhumanismo: entre el mejoramiento y la aniquilación”, Investigación y Ciencia, número monográfico sobre el futuro, noviembre de 2016.

Antonio Diéguez, Transhumanismo. La búsqueda tecnológica del mejoramiento bumano, Madrid, Herder, 2017.

A. Llano (a), Otro modo de pensar, Pamplona, EUNSA, 2016;

A. Llano (b), Maravilla de maravillas: conocemos, Pamplona, EUNSA, 2016.

L. Polo, Quién es el hombre. Un espiritu en el tiempo, Madrid, Rialp, 1992.

C. Riaza, "Crecimiento irrestricto y libertad en el pensamiento de Leonardo Polo", en Anuario Filosófico, 1996 (29), 985-991.

M.-À. Serra, "Mejoramiento humano en el tercer milenio. Mitos y realidades", en A. Cortina, M.-À. Serra (cords.), Humanidad. Desafios éticos de las tecnologías emergentes, Madrid, Ediciones Internacionales Universitarias, 2016

R. Solé, La lógica de los monstruos. ¿̇Hay alternativas a la naturaleza tal y como la conocemos?, México, Tusquets, 2016.

J. Torres López, Filosofía biológica de Leonardo Polo, Pamplona, EUNSA, 2016,

Héctor Velázquez Fernández hector.velazquez@upaep.mx 